\title{
Free-Standing Polyelectrolyte Membranes Made of Chitosan and Alginate
}

\author{
Sofia G. Caridade, ${ }^{\dagger, \downarrow \S}$ Claire Monge, ${ }^{\S}$ Flora Gilde, ${ }^{\S}$ Thomas Boudou, ${ }^{\S}$ João F. Mano, ${ }^{* \dagger, \ddagger}$ \\ and Catherine Picart*, ${ }^{*}$
}

\begin{abstract}
${ }^{\dagger} 3 \mathrm{~B}$ ’s Research Group, Biomaterials, Biodegradables, and Biomimetics, University of Minho, Headquarters of the European Institute of Excellence on Tissue Engineering and Regenerative Medicine AvePark, 4806-909, Taipas, Guimarães, Portugal

${ }^{\ddagger}$ PT Government Associate Laboratory, ICVS/3B’s, Braga/Guimarães, Portugal

${ }^{\S}$ CNRS UMR 5628, LMGP, Institut National Polytechnique de Grenoble and Centre National de la Recherche Scientifique, 3 parvis Louis Néel, F-38016 Grenoble, France
\end{abstract}

ABSTRACT: Free-standing films have increasing applications in the biomedical field as drug delivery systems for wound healing and tissue engineering. Here, we prepared freestanding membranes by the layer-by-layer assembly of chitosan and alginate, two widely used biomaterials. Our aim was to produce a thick membrane and to study the permeation of model drugs and the adhesion of muscle cells. We first defined the optimal growth conditions in terms of $\mathrm{pH}$ and alginate concentration. The membranes could be easily detached from polystyrene or polypropylene substrate without any postprocessing step. The dry thickness was varied over a large range from 4 to $35 \mu \mathrm{m}$. A 2 -fold swelling was observed by confocal microscopy when they were immersed in PBS. In addition, we quantified the permeation of model drugs (fluorescent dextrans) through the free-standing membrane, which depended on the dextran molecular weight. Finally, we showed that myoblast cells exhibited a preferential adhesion on the alginate-ending membrane as compared to the chitosan-ending membrane or to the substrate side.

\section{INTRODUCTION}

The method for preparing polyelectrolyte multilayer (PEM) films by the consecutive deposition of oppositely charged polyelectrolytes has gained a high interest due the user-friendly preparation, possibility to incorporate various biomolecules, fine control over the film architecture and robustness of the production under ambient and physiological conditions. ${ }^{1,2}$ This nanoscale control can be obtained simply by varying the deposit conditions such as $\mathrm{pH}^{3,4}$ ionic strength, ${ }^{5}$ polymer functionality and charge density. ${ }^{6}$ In addition, polymer concentration plays an important role in film growth. ${ }^{7}$ In particular, combining $\mathrm{pH}$ amplified growth ${ }^{8}$ with a variation in the polyelectrolyte concentration ${ }^{9}$ can lead to very thick assemblies in a minimal number of deposition steps.

Both synthetic and natural polyelectrolytes have been used as building blocks for LbL-based nano- and micro-objects. ${ }^{2,10}$ The main advantage of using synthetic polymers is the possibility to adjust several parameters over a larger range (e.g., ionic strength and $\mathrm{pH}$ of assembly) and also their resistance to a larger number of physical and chemical stresses. Furthermore, they are easy to chemically modify.

In vivo, natural tissues are composed of cells embedded in an extracellular matrix made of proteins, polysaccharides, and other bioactive molecules such as growth factors. ${ }^{11}$ Thus, a closer step to recreating original tissues, with which cells interact in vivo, is to use extracellular matrix components as building blocks for the films. Natural polymers have shown great potential in the biomedical field ${ }^{12}$ in view of their structural similarities with natural extracellular matrices and biodegradability properties. Polysaccharides are especially interesting as they are highly hydrated, biocompatible, and often biodegradable. In addition, they can be easily processed into PEM films. ${ }^{10,13}$

In view of their versatility, supported LbL films have begun to be explored for biomedical applications, including biosensors, drug delivery, coating of biomaterials, and tissue engineering., ${ }^{2,14}$ Besides, colloidal templates or supporting materials can be used to prepare various types of LbL-based objects, including individual coated cells, ${ }^{15}$ encapsulated cell aggregates, ${ }^{16}$ hollow capsules, ${ }^{17}$ or free-standing membranes. ${ }^{18}$ In these latter cases, the underlying substrate, either a colloidal template or a supporting material has to be removed, which is a difficult step, as defects can be introduced or roughness may be changed. ${ }^{19-21}$

Until now, the development of free-standing (FS) films has mostly focused on synthetic or nanocomposite films that are transparent, mechanically robust, and electrically conductive. ${ }^{18,19,22}$ Their thermal properties have also been studied. ${ }^{21}$

Received: March 2, 2013

Revised: April 10, 2013

Published: April 16, 2013 
To date, studies on free-standing (FS) films made entirely of polysaccharide are still scarce. ${ }^{23,24}$ The difficulties come from the detachment step, the lack of cohesion of these membranes and their manipulation. Takeoka et al..$^{23}$ succeeded in preparing ultrathin FS chitosan/alginate (CHI/ALG) membranes of 2.9 $\mathrm{nm}$ per layer pair, which had to be supported by a water-soluble poly(vinyl alcohol) membrane for their manipulation. They used it to repair a visceral pleural defect in dogs. Rajagopalan et al. focused on the detachment step of a polysaccharide membrane. ${ }^{24}$ To this end, they studied eight different experimental conditions by varying the number of layer pairs, the deposition time, and the polymer concentration and built $\mathrm{CHI} /$ hyaluronan $(\mathrm{CHI} / \mathrm{HA})$ films on a low energy substrate. It was only for a single experimental condition that they could produce a detachable and robust, $\sim 3.5 \mu \mathrm{m}$ thick, membrane. An additional cross-linking step was needed to render this membrane stable in a physiological buffer.

In the present study, our aim was to produce a thick polysaccharide membrane (in the tens of $\mu \mathrm{m}$ range) that could be subsequently used for drug delivery and tissue engineering. Biocompatible (CHI/ALG) FS membranes made of 25-200 layer pairs, with a corresponding dry thickness of $4-35 \mu \mathrm{m}$, were prepared by detachment from an underlying inert substrate without any postprocessing step. CHI and ALG were selected for their abundance and versatility. $\mathrm{CHI}$ is a cationic polysaccharide obtained from the $\mathrm{N}$-deacetylation of chitin, which is an abundant polysaccharide found in crustacean shells. ${ }^{25,26}$ ALG is extracted from algae. ${ }^{27}$ It is an extremely versatile and adaptable material with tunable physicochemical properties. ${ }^{28}$ Both CHI and ALG are already widely used in biomedical applications and are typical components of wounddressing materials. ${ }^{27,29}$ ALG is also used for cell encapsulation. ${ }^{26,30}$

The FS membranes made of PEM films were detached from an underlying inert substrate and were stable in a physiological buffer without any postprocessing step. In addition, they enabled the permeation of model drugs. Finally, we showed that the myoblast cells could adhere on the membrane, the alginate-ending membranes being preferred by the cells.

\section{MATERIALS AND METHODS}

Materials. CHI (medium molecular weight) was purchased from Sigma-Aldrich (Germany) and was purified prior to use. The degree of $\mathrm{N}$-deacetylation (DD) was found to be $78 \%$ by the first derivative ultraviolet spectrophotometry, using both glucosamine (GluN) and $\mathrm{N}$ acetylglucosamine (GluNAc) standards for calibration. ${ }^{31}$ The molecular weight $\left(M_{\mathrm{v}}\right)$ was determined by viscometry in $\mathrm{CH}_{3} \mathrm{COOH}(0.5$ $\mathrm{M}) / \mathrm{NaCH}_{3} \mathrm{COO}(0.2 \mathrm{M})$, which was found to be $770 \mathrm{kDa}$ according to the Mark-Houwing theory $\left(k=3.5 \times 10^{-4} ; a=0.76\right){ }^{32}$ Sodium alginate derived from brown algae (ALG, A2158, low viscosity: 136 $\mathrm{mPa} . \mathrm{s})$ and fluorescein isothiocyanate dextran, FITC-dextran, with molecular weights of 4000, 40000, and 70000 (noted FD4, FD40, and FD70, respectively) were obtained from Sigma and used as received. Alexa-Fluor 568 was purchased from Invitrogen. All reagents and solvents were used without further purification. For staining of the cell cytoskeleton, rhodamine phalloidin (P2141) was purchased from Sigma.

Buildup of (CHI/ALG) Multilayer Films. Multilayer films were built on four different substrates: silicon wafers ( $\mathrm{Si}$ ), polystyrene (PS), polypropylene (PP), and Teflon (PTFE). Prior to film deposition, they were cleaned with ethanol and rinsed thoroughly with water before being dried with a stream of nitrogen. The polyelectrolyte solutions were freshly prepared at various concentrations $(1,3$, or 5 $\mathrm{mg} / \mathrm{mL}$ ). For the adjustment of $\mathrm{pH}$, an acetate buffer was prepared at $\mathrm{pH} 3$ or 5 using appropriate volumes of $0.1 \mathrm{M}$ acetic acid and $0.1 \mathrm{M}$ sodium acetate. Solutions were prepared in this buffer (in the absence of additional salt) or in the presence of $0.15 \mathrm{M} \mathrm{NaCl}$ at $\mathrm{pH}$ 5.5. The different conditions tested are named using the following nomenclatures: $(\mathrm{CHI} / \mathrm{ALG}) c_{\mathrm{C}} / c_{\mathrm{A}}$ and $\mathrm{pH} \mathrm{C}_{\mathrm{C}} / \mathrm{pH}_{\mathrm{A}}$, where $c_{\mathrm{C}}$ and $c_{\mathrm{A}}$ represent the concentration of $\mathrm{CHI}$ and $\mathrm{ALG}$, respectively, and $\mathrm{pH}_{\mathrm{C}}$ and $\mathrm{pH}_{\mathrm{A}}$ represents the $\mathrm{pH}$ of $\mathrm{CHI}$ and $\mathrm{ALG}$, respectively. For example, a film built with $\mathrm{CHI}(1 \mathrm{mg} / \mathrm{mL}, \mathrm{pH} 5)$ and ALG $(5 \mathrm{mg} / \mathrm{mL}, \mathrm{pH} 3)$ is noted CHI/ALG $1 / 5 \mathrm{pH} 5 / 3$.

The substrates were first dipped in the CHI solution for 5 min then rinsed twice in water (with the same $\mathrm{pH}$ as the $\mathrm{CHI}$ solution) for 2 min. Subsequently, they were immersed in ALG solution for $5 \mathrm{~min}$ followed by rinsing twice in water (with the same $\mathrm{pH}$ as the ALG solution) for a period of $2 \mathrm{~min}$. This procedure was repeated until the desired number of layer pairs was achieved to prepare the (CHI/ ALG) $)_{i}$ multilayer films, $i$ being the number of layer pairs.

Fourier Transform Infrared Spectroscopy (FTIR). The chemical structure of dry PEM films was investigated by FTIR spectroscopy in transmission mode with a Vertex 70 spectrophotometer (BrukerOptic Gmbh, Ettlingen, Germany) equipped with a MIR detector. All spectra were recorded between 400 and $4000 \mathrm{~cm}^{-1}$ with a $2 \mathrm{~cm}^{-1}$ resolution using Blackman-Harris three-term apodization and the standard Bruker OPUS/IR software v6.5 (Bruker Optic Gmbh). For the supported films, silicon was used as substrate and bare Si was taken as reference. Film buildup was followed step-bystep from 2 to 12 layer pairs. After deposition of 2 layer pairs, the film was dried and the spectrum was recorded. This procedure was repeated every other layer pairs until 12 layer pairs have been deposited. For the analysis of FS membranes, the membranes were studied after detachment and the spectrum of air was taken as reference. The FITR spectra of the (CHI/ALG) $)_{i}$ free-standing films made of an increasing number of layer pairs were acquired.

Membrane Thickness and Scanning Electron Microscopy (SEM) Observations. The morphological analysis of the (CHI/ ALG) $)_{100}$ free-standing films was performed after detachment of the films from their substrate. Membrane thickness was measured using a micrometer (Mitutoyo, Japan). The measurements were done on membranes prepared from two different runs of robot (using freshly prepared polyelectrolyte solutions). At least three FS membranes were measured for each condition and for each membrane the thickness was measured at three different locations.

The morphological analysis of the $(\mathrm{CHI} / \mathrm{ALG})_{100}$ free-standing films was performed after detachment using SEM (Quanta FEG 250 Fei) where both sides of the membranes were observed in high vacuum with a Everhart-Thornley Detector (ETD detector for secondary electrons). For the cross section observation, the detached free-standing were immersed in liquid nitrogen until free fracture. After that, the free fracture was placed at $45^{\circ}$ and observed also in high vacuum.

Atomic Force Microscopy (AFM) Imaging. Dried PEM membranes were imaged using a BioCatalyst (Bruker AXS SAS, Palaiseau, France) equipped with a $150 \mu \mathrm{m}$ scanner in the intermittent-contact mode. We used a ScanAsyst-Air cantilever (Bruker) with a resonance frequency of $70 \mathrm{kHz}$ and a spring constant of $0.4 \mathrm{~N} / \mathrm{m}$. Substrate topographies were imaged with $512 \times 512$ pixels $^{2}$ at line rates of $1 \mathrm{~Hz}$. For surface roughness analysis, $5 \times 5 \mu \mathrm{m}^{2}$ AFM images were obtained and the root mean squared roughness $R_{\mathrm{RMS}}$ from the principal $\mathrm{x}-\mathrm{y}$ plane was calculated The analysis of the images was performed using NanoScope Analysis (Bruker).

Permeability. The permeability measurements were conducted using a glass Franz-type diffusion cell (PermeGear) with a $8 \mathrm{~mL}$ reactor compartment (effective mass transfer area of $1 \mathrm{~cm}^{2}$ ). The membranes were previously equilibrated in a PBS solution for $1 \mathrm{~h}$, placed between the two compartments and hold with a stainless steel clamp. The receptor compartment was immediately filled with PBS solution and air bubbles were removed. Finally, the donor compartment was filled with $5 \mathrm{mg} / \mathrm{mL}$ of FITC-dextran. Aliquots of $200 \mu \mathrm{L}$ were withdrawn from the receptor compartment at predetermined time periods and replenished by fresh PBS. The experiments were performed at room temperature (ca. $20{ }^{\circ} \mathrm{C}$ ) and the receptor compartment was stirred at $400-600 \mathrm{rpm}$ using a magnetic bar to 

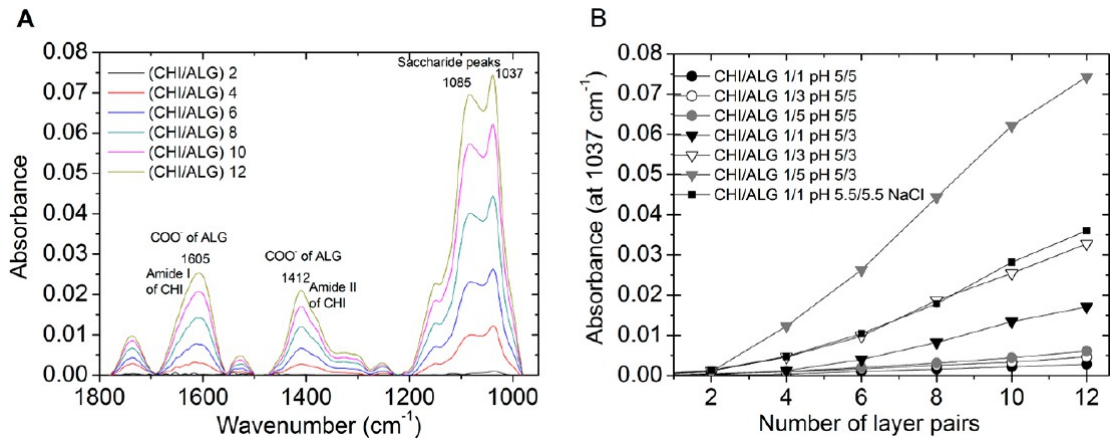

Figure 1. FTIR spectra of (CHI/ALG) multilayer films. (A) Representative FTIR spectra of (CHI/ALG) multilayer films acquired during the buildup of a film made of 12 pairs of layers. The film was deposited on a silicon substrate. The major bands are indicated on the graph (saccharide peaks, carboxylic groups, and amide I and II bands). (B) Film growth followed by the absorbance of the most intense saccharide peak (at $1037 \mathrm{~cm}^{-1}$ ) in function of the ALG concentration (from 1 to $5 \mathrm{mg} / \mathrm{mL}$ ) and of the $\mathrm{pH}(\mathrm{pH}$ of ALG fixed to 5 or 3).

eliminate the boundary layer effect. The time-dependent concentration of each FITC-dextran in the receptor chamber was assessed by a microplate reader (Tecan Infinite M1000). The fluorescence was read at $520 \mathrm{~nm}$ and independent calibration curves were determined for each FITC-dextran (FD4, FD40, and FD70). The initial concentration of the donor solution was accurately assessed using the same method.

The diffusion coefficient $(D)$ was calculated according the Fick's law as follows:

$$
D=\frac{P \cdot h}{K_{\mathrm{d}}}
$$

where $P$ is the permeability, $h$ is the thickness of the membrane, and $K_{\mathrm{d}}$ is the partition coefficient. The permeability of FD4, FD40, and FD70 was calculated by the following equation: ${ }^{33}$

$$
\ln \left(1-\frac{2 C_{t}}{C_{0}}\right)=\frac{2 A}{V} \cdot P \cdot t
$$

where $C_{t}$ is the concentration in the receptor compartment at time $t$, $C_{0}$ is the initial concentration in the donor compartment, $V$ is the solution volume in the two compartments, and $A$ is the effective area of permeation. By plotting $(V / 2 A) \cdot \ln \left(1-2 C_{t} / C_{0}\right)$ versus $t$, the permeability coefficient was calculated from the slope.

The partition coefficient is defined as the equilibrium ratio of the solute concentration in a porous material to that in bulk solution as

$$
K_{\mathrm{d}}=\frac{V_{\mathrm{s}}\left(C_{\mathrm{i}}-C_{\mathrm{s}}\right)}{V_{\mathrm{m}} C_{\mathrm{s}}}
$$

where $C_{\mathrm{s}}$ represents the solute concentration at the equilibrium state, $C_{\mathrm{i}}$ is the initial solute concentration in the solution, and $V_{\mathrm{s}}$ and $V_{\mathrm{m}}$ are the volume of the solution and the polymer membrane, respectively.

Confocal Laser Scanning Microscopy (CLSM). For CLSM observations, the films were observed with an LSM700 confocal microscope (Carl Zeiss SAS, Le Pecq, France). Images were acquired in air or in PBS.

Chitosan Labeling. For CLSM measurements, CHI was fluorescence labeled using Alexa 568 (Invitrogen) following the manufacturer's protocol, except that the reaction was carried out for 2 $\mathrm{h}$ at $\mathrm{pH}$ 6.0. A Sephadex G-25 size exclusion column (PD-10, Amersham Bioscience, Sweden) was used to purify the product and remove any unbound dye.

In Vitro Cell Culture Studies. Direct contact assays to assess cell adhesion were performed on $10 \times 10 \mathrm{~mm}^{2}$ samples cut from (CHI/ ALG) membranes made of 200 layer pairs. Prior to culturing, all samples were sterilized 30 min under UV light. C2C12 myoblasts (from ATCC, U.S.A.; <20 passages) were used in the preliminary cell culture studies. The cells were cultured in 1:1 Dulbecco's modified Eagle's medium (DMEM)/Ham's F12 medium (growth medium [GM]) supplemented with $10 \%$ of heat inactivated fetal bovine serum (FBS; Biochrom AG, Germany) and $10 \mathrm{U} / \mathrm{mL}$ penicillin $\mathrm{G}$ and 10 $\mathrm{mg} / \mathrm{mL}$ streptomycin (Gibco, U.S.A.) in a humidified atmosphere with $5 \%$ of $\mathrm{CO}_{2}$. At confluence, cells were trypsinized, seeded onto the membrane's surface with a cellular density of $3 \times 10^{4}$ cells $/ \mathrm{cm}^{2}$. Cells were cultured for $24 \mathrm{~h}$ in GM.

For fluorescent staining, $\mathrm{C} 2 \mathrm{C} 12$ myoblasts were fixed in a solution of $3.7 \%$ of formaldehyde in TBS $(0.15 \mathrm{M} \mathrm{NaCl}, 50 \mathrm{mM}$ Tris- $\mathrm{HCl}, \mathrm{pH}$ 7.4) for $20 \mathrm{~min}$ and permeabilized for $4 \mathrm{~min}$ in TBS containing with $0.2 \%$ of Triton X-100. Then the cells were incubated $10 \mathrm{~min}$ in TBS containing both rhodamine-phalloidin $(1: 800)$ for actin staining and DAPI $(0.5 \mu \mathrm{g} / \mathrm{mL})$ for nucleus staining. For confocal microscopy observations, the (CHI/ALG) membranes were deposited in between two $25 \mathrm{~mm}$ diameter glass coverslips maintained by an Attofluor chamber (Invitrogen).

\section{RESULTS AND DISCUSSION}

Optimization of Film Buildup Conditions. Different conditions were tested for the production of (CHI/ALG) multilayer films. CHI and ALG are both weak polyelectrolytes, being only partially charged at moderate $\mathrm{pH}$ near their $\mathrm{pK}$. Thus, the $\mathrm{pH}$ and ionic strength are expected to influence film growth. ${ }^{4}$ The $\mathrm{pH}$ of ALG was set at 5 or 3 and its concentration was increased from 1 to $5 \mathrm{mg} / \mathrm{mL}$. Due to the limited solubility of $\mathrm{CHI}$, we decided to work at constant $\mathrm{CHI}$ concentration (1 $\mathrm{mg} / \mathrm{mL})$ and fixed $\mathrm{pH}(\mathrm{pH}=5)$. Furthermore, we compared film growth in a medium containing no salt or added salt. Film buildup was characterized by FTIR (Figure 1). All the conditions studied allowed the construction of the (CHI/ ALG) multilayer films. Figure 1A shows representative FTIR spectra acquired at different steps of a $(\mathrm{CHI} / \mathrm{ALG})_{12}$ film buildup. Three main regions can be observed. The more intense region of $950-1200 \mathrm{~cm}^{-1}$ represents the characteristic saccharide peaks of $\mathrm{CHI}$ and $\mathrm{ALG}$ that are representative of the skeletal vibrations and involves $\mathrm{C}-\mathrm{O}$ and $\mathrm{C}-\mathrm{O}-\mathrm{C}$ stretching peaks at 1085,1037 , and $1151 \mathrm{~cm}^{-1}$.34,35 The band at $1420-$ $1500 \mathrm{~cm}^{-1}$ contains the amide II band from $\mathrm{CHI}$ and the smaller but broader band at $1412 \mathrm{~cm}^{-1}$ is attributed to the -COO- symmetric stretch of ALG. ${ }^{36}$ The $1630-1700 \mathrm{~cm}^{-1}$ region corresponds to the amide $\mathrm{I}(-\mathrm{NH}-\mathrm{C}=\mathrm{O}$ stretching doublets) vibrations of $\mathrm{CHI}$, the peak at $1605 \mathrm{~cm}^{-1}$ can be attributed to -COO- asymmetric stretch from ALG. ${ }^{37}$ Finally, the peaks that appear at around 1620 and $1660 \mathrm{~cm}^{-1}$ correspond to the $\mathrm{C}=\mathrm{O}$ bands of $\mathrm{CHI} .{ }^{34,38}$

During film buildup, the absorbance increased with the successive depositions of polyelectrolyte, indicative of film growth. This increase in absorbance was mainly verified on the saccharide peaks at 1037 and $1085 \mathrm{~cm}^{-1}$, on the $\mathrm{COO}^{-}$of ALG at $1605 \mathrm{~cm}^{-1}$ and on the amide bands of $\mathrm{CHI}$. To have more 
insight about film growth of the multilayer films, the absorbance at $1037 \mathrm{~cm}^{-1}$ was plotted against the number of layers (Figure 1B). We observed that, for a given $\mathrm{pH}$ of 5 , film growth was very similar when ALG concentration was increased from 1 to $5 \mathrm{mg} / \mathrm{mL}$. However, the effect of ALG concentration was noticeable when the $\mathrm{pH}$ of ALG was lowered to 3. For comparison, a film built in a medium containing $0.15 \mathrm{M} \mathrm{NaCl}$ is also shown. The addition of salt $(\mathrm{NaCl})$ in the polyelectrolyte solutions also promote a faster buildup that is related with a screening effect over the charge of the polyelectrolytes solutions that regulates the ionic force of the polymeric solutions. ${ }^{5,39}$ From this data, we concluded that the (CHI/ ALG) $1 / 5 \mathrm{pH} 5 / 3$ formulation, that is, high alginate concentration and only partial ionization, resulted in the fastest film growth. These results are consistent with those reported by Shen et al., ${ }^{9}$ who investigated the effect of hyaluronan (HA) concentration in poly(L-lysine) (PLL)/HA film growth.

Free-Standing Membranes Made of (CHI/ALG). Based on the results obtained on film growth, we selected the (CHI/ ALG) $1 / 5 \mathrm{pH} \mathrm{5/3}$ film for further studies. In a first step, we investigated whether detachment of the films from a substrate was possible without any postprocessing step. To this end, four types of substrates Si, PP, PS, and PTFE, were selected in view of their hydrophobicity. Weak van der Waals interactions are established between the polyelectrolytes and the substrate, allowing the production of defect-free FS films that were easily peeled from the substrate. ${ }^{21,24,40}$ We noticed that the (CHI/ ALG) ${ }_{100}$ multilayer films built on Si were not robust and that those built on PTFE substrate were not detachable. On the contrary, $(\mathrm{CHI} / \mathrm{ALG})_{100}$ multilayer films built on PP and PS substrates were both robust and detachable by just letting them dry (Figure 2A). They could be easily handled with tweezers and can be cut to any shape with scissors. FTIR spectra of the free-standing membranes confirmed that the (CHI/ALG) membranes (Figure $2 \mathrm{~B}$ ) possessed a similar secondary structure to that of the supported films (Figure 1). Indeed, FTIR spectra could be superposed. In addition, spectra of membranes prepared using PP and PS substrates were similar (Figure 2B), indicating no influence on the underlying substrate on the bulk film structure. SEM observations of the upper side of (CHI/ $\mathrm{ALG})_{100}$ membranes ending by ALG or CHI (Figure 2C) revealed a certain roughness as compared to the "substrate" side of the membrane (i.e., the side that was in contact with the substrate prior to detachment of the film; Figure 2D). The polysaccharide membrane was also observed in cross section (Figure 2D), revealing some porosity. Such property may be interesting for tissue engineering applications as porosity has a significant role in controlling the diffusion of nutrients and gases to the cells. ${ }^{41}$ AFM imaging of the membrane was also realized at higher resolution (Figure 3), which allowed quantitative roughness measurements to be made (Figure 3D). The roughness $\left(r_{\mathrm{RMS}}\right)$ was similar for the substrate side $(65 \pm 13 \mathrm{~nm})$ and the ALG-ending membrane $(72 \pm 13 \mathrm{~nm})$, but it was higher for the CHI-ending side $(104 \pm 23 \mathrm{~nm})$. Similar observations of increased roughness for films produced in $\mathrm{pH}$-amplified conditions were made by Shiratori and Rubner $^{4}$ and Shen et al. for films made at different $\mathrm{pH}^{9}$ Indeed, Shiratori and Rubner demonstrated that the conformational state of a multilayer surface comprising a significant population of loops and tails produced, upon drying, a molecularly rough surface whereas a surface dominated by flat, train-like segments conducted to a more smooth surface. ${ }^{4}$
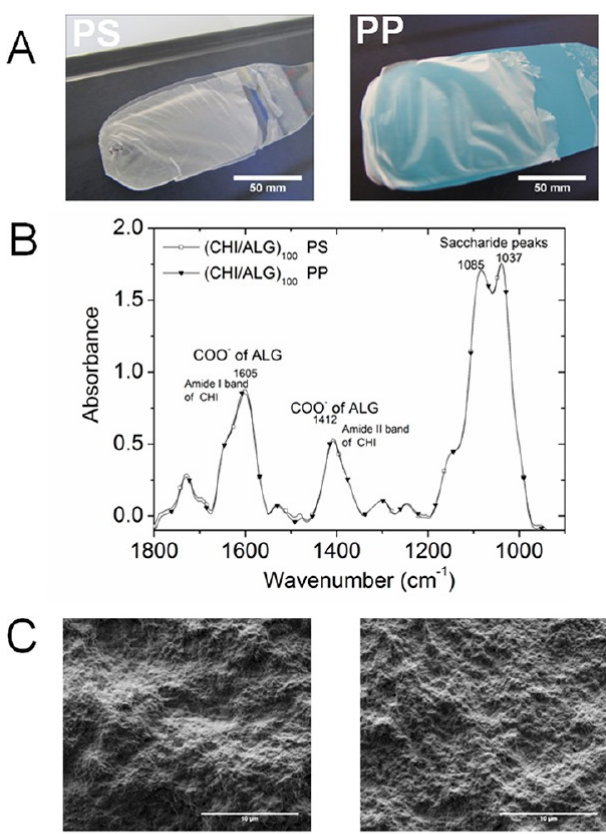

ALG-ending side
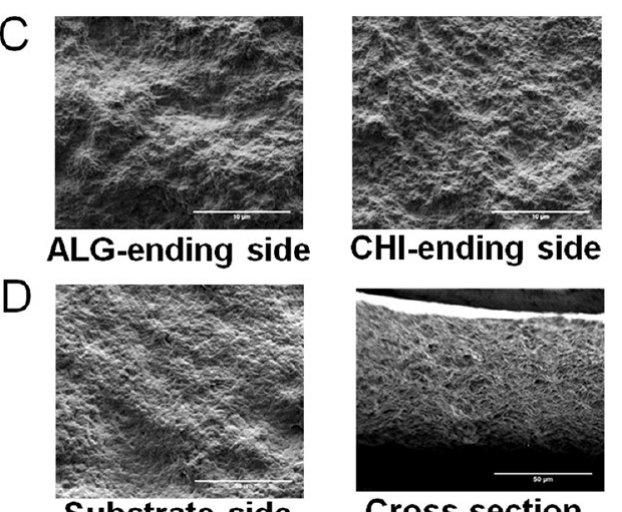

Substrate side

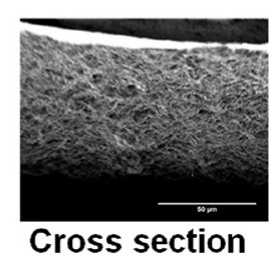

Figure 2. Free-standing (CHI/ALG) membranes. (A) Images of $(\mathrm{CHI} / \mathrm{ALG})_{100}$ free-standing films obtained on polystyrene (PS) and polypropylene (PP). (B) Corresponding FTIR spectra of the (CHI/ ALG $)_{100}$ free-standing films made from PS or PP as substrates. (C) SEM observations of the upper side of the membrane ending either by ALG or CHI, i.e., (CHI/ALG)100 and (CHI/ALG)100-CHI. (D) SEM images of the substrate side of the membrane, i.e., the side that have been in contact with the PP substrate prior to detachment, and of a cross-section of a (CHI/ALG) ${ }_{100}$ membrane (scale bar for C-D: 10 $\mu \mathrm{m}$ for top views and $50 \mu \mathrm{m}$ for cross-section).

Control of Membrane Thickness. In a second step, we investigated the influence of the number of layer pairs on (CHI/ALG) membrane thickness. Figure 4A shows FTIR spectra of membranes made of 25, 50, 100, and 200 layer pairs produced after film detachment from PP substrates. Here again, similar secondary structures were observed. An increase in absorbance was confirmed for the major structures, that is, saccharide rings, carboxylic groups, and amide groups. Plotting the absorbance of saccharide rings (at $1037 \mathrm{~cm}^{-1}$, Figure $4 \mathrm{~B}$ ) as a function of the number of layers revealed a linear increase with the number of layers. Indeed, membrane thickness also increased linearly with the number of layer pairs (Figure 4C). Thus, our results were consistent with the previous observations of film linear growth when the number of deposited layer was very high. ${ }^{42}$ (CHI/ALG) membrane dry thickness increased from $\sim 4 \mu \mathrm{m}$ for 25 layer pairs to $\sim 33 \mu \mathrm{m}$ for 200 layer pairs. In conclusion, membrane thickness can be easily modulated over a large range depending on the number of layer pairs. To note, this free-standing film thickness, which corresponds to $165-260 \mathrm{~nm}$ per layer pair, is much thicker than what has been previously obtained for FS membranes using other polyelectrolytes and deposit conditions. For instance, Lutkenhaus et al. ${ }^{21}$ reported a thickness of $8 \mu \mathrm{m}$ for 


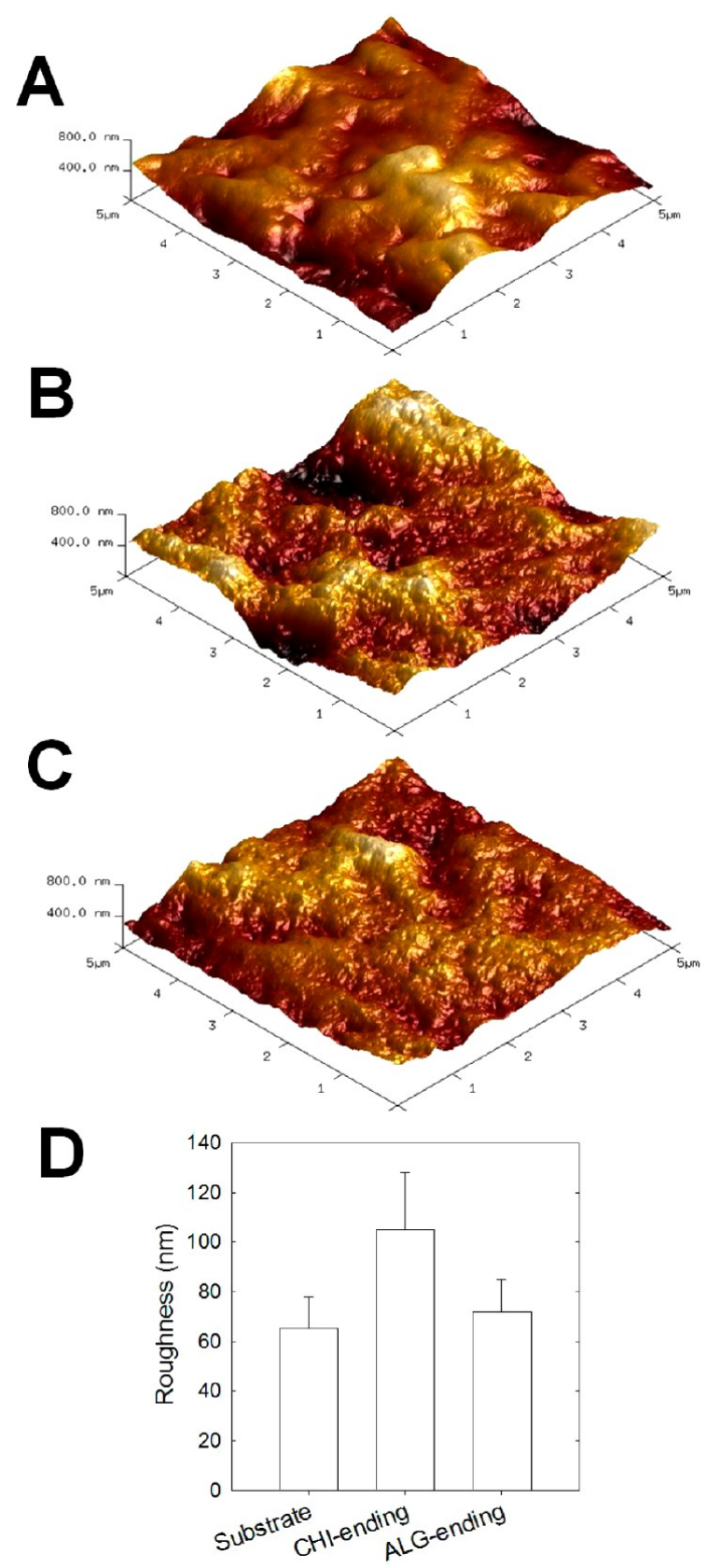

Figure 3. Atomic force microscopy images $\left(5 \times 5 \mu \mathrm{m}^{2}\right)$ of (CHI/ ALG) free-standing membranes ( $z$ scale $800 \mathrm{~nm}$ ): (A) substrate side of the membrane, (B) CHI-ending membrane, (C) ALG-ending membrane, and (D) corresponding roughness analysis $\left(r_{\mathrm{RMS}}\right)$.

a FS film made of 100 layer pairs of poly(ethylene oxide) (PEO) and poly(acrylic acid) (PAA) (ie about $80 \mathrm{~nm}$ per layer pair).

Larkin et al. ${ }^{24}$ using $\mathrm{CHI}$ and $\mathrm{HA}$ as building blocks of their FS membranes reported thicknesses in the range 1.8 to $3.6 \mu \mathrm{m}$ for the membranes made of 30 and 50 layer pairs (ie about 60$70 \mathrm{~nm}$ per layer pair). In addition, the thinnest membranes of $1.8 \mu \mathrm{m}$ were not manipulable.

In our case, the $\mathrm{pH}$-amplified conditions for the film buildup can explain such large thickness increment per deposited layer pair. Indeed, our data are compatible with previous observations of notable $\mathrm{pH}$ and concentration effects of the polyelectrolytes $^{3,4}$ and with our recent data on the $\mathrm{pH}$ amplified growth of poly(L-lysine)/HA multilayer films. ${ }^{7}$
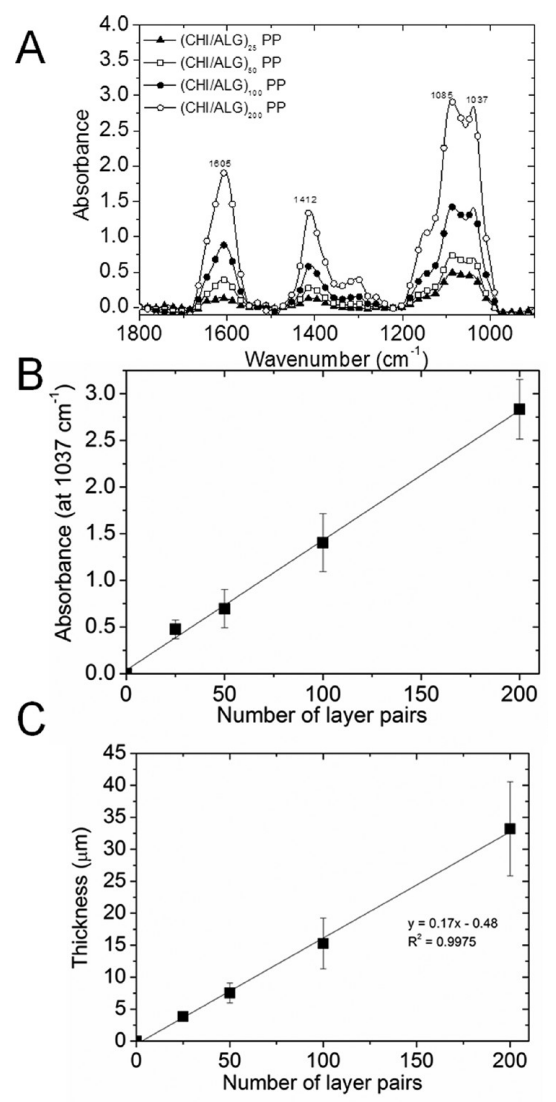

Figure 4. (A) FTIR spectra of (CHI/ALG) membranes made of an increasing number of layer pairs from 25 to 200. (B) Absorbance at $1037 \mathrm{~cm}^{-1}$ (saccharide ring) vs number of layers. (C) Corresponding thickness vs number of layer pairs. Linear fits are also plotted for the absorbance and thickness (mean \pm SD of 5 measurements made on different FS membranes for FTIR and 12 measurements for thickness measurement).

Permeability. To assess the permeability of the (CHI/ ALG) membrane, we quantified the permeation of model macromolecules, for example, FITC-dextran (FD) of different molecular weights, which were used here as to assess the influence of molecular size ${ }^{43}$ (Figure 5). Figure 5A shows representative diffusion profiles of $\mathrm{FD}$ through a (CHI/ALG) membrane made of 100 layer pairs. A faster permeation was

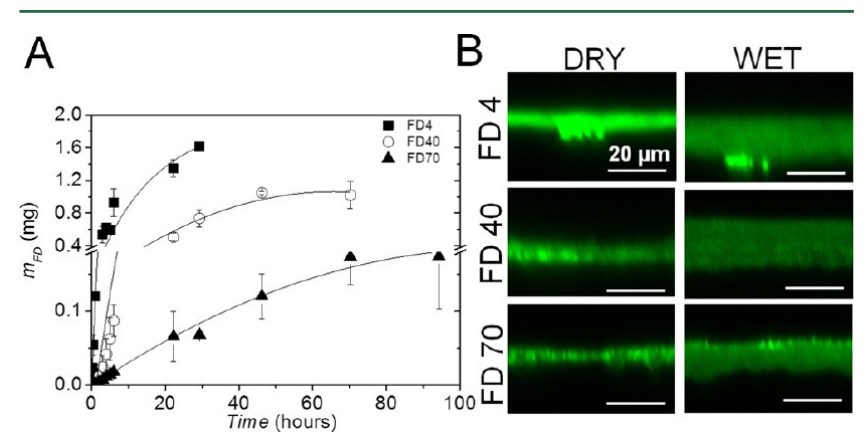

Figure 5. Diffusion of FITC-dextran (FD) of different molecular weights through a (CHI/ALG) membrane made of 100 layer pairs. (A) Transport profile of FD4, FD40, and FD70 through the (CHI/ ALG) ${ }_{100}$ membrane. The mass of FD is plotted as a function of the time. (B) CLSM observations of FD in the (CHI/ALG) ${ }_{100}$ membranes after the permeability measurement. 
observed for the low molecular weight FD4 as compared to FD40 and FD70. Moreover, a linear profile was observed over the initial time points, which corresponded to the pseudosteady-state. After the permeation experiments, the (CHI/ ALG) membrane were observed by CLSM both in dry and wet states (Figure 5B). A homogeneous fluorescence in the $z$ direction over $\sim 10 \mu \mathrm{m}$ was observed for FD4 indicating that it diffused homogeneously through the whole membrane. This was not the case for FD70, for which a heterogeneous fluorescence was observed with some brighter regions than others, revealing less permeable regions. FD40 presented an intermediate behavior. These data suggested that some FD molecules get entrapped inside the membrane, indicating that it may be used as reservoir for controlled release of molecules. ${ }^{44}$

In the wet state, the fluorescence was visible over a $\sim 20 \mu \mathrm{m}$ thickness for FD4 and FD40 but over only $\sim 15 \mu \mathrm{m}$ for FD70. This confirmed the swelling of the membrane in the wet state as compared to dry state. Overall, these fluorescence observations of FITC-dextran were consistent with the quantitative results obtained from the permeation experiment.

Taking the initial conditions of the tests and the evolution of the concentration of FD in the receptor compartment allowed us to deduce the permeability coefficient $(P)$ from eq 2 (Figure $6 \mathrm{~A})$. A short lag time was visible at the beginning of each permeation curve, which may be attributed to the time needed
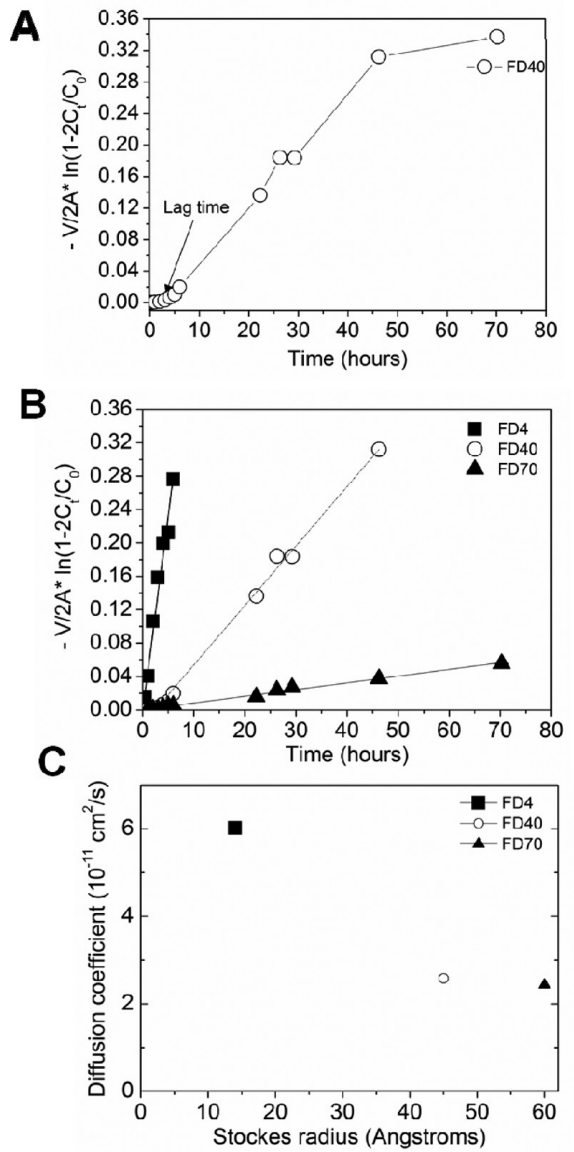

Figure 6. Quantitative diffusion of FD measured using a Franz-type diffusion cell. (A) Typical diffusion curve of FD40 through a (CHI/ ALG) ${ }_{100}$ membrane. (B) Permeation of the different FD through the (CHI/ALG) $)_{100}$ membrane. (C) Influence of molecular size of the FD on the diffusion coefficient. to establish a quasi-steady state diffusion in the absence of solute-polymer interaction. The permeability coefficients were calculated only from the linear permeation region (Figure 6B). An increase in permeability of FD was noted with a decrease in its molecular weight (Figure 6B and Table 1). The partition

Table 1. Permeability, Partition Coefficients, and Diffusion Coefficients of FITC-Dextrans in (CHI/ALG) $)_{100}$ FS Membranes

\begin{tabular}{lccc}
$\begin{array}{c}\text { FITC- } \\
\text { dextran }\end{array}$ & $\begin{array}{c}\text { permeability, } P \\
\left(10^{-6} \mathrm{~cm} / \mathrm{s}\right)\end{array}$ & $\begin{array}{c}\text { partition } \\
\text { coefficient, } k_{\mathrm{d}}\end{array}$ & $\begin{array}{c}\text { diffusion coefficient, } D, \\
10^{-11}\left(\mathrm{~cm}^{2} / \mathrm{s}\right)\end{array}$ \\
\hline FD4 & 1.5 & 889 & 6.0 \\
FD40 & 2.1 & 290 & 2.6 \\
FD70 & 0.3 & 38 & 2.4 \\
\hline
\end{tabular}

coefficients were deduced from eq 3 and, finally, the diffusion coefficients $(D)$ were deduced from eq $1 . K_{\mathrm{d}}$ values were larger than unity, which indicated that a larger amount of the solutes was present in the membrane as compared to that in ambient bulk solution. ${ }^{45}$ As anticipated, the diffusion coefficient decreased with the increase in Stokes radius of FD (Figure $6 \mathrm{C}){ }^{46}$

To get better insight into the behavior of the (CHI/ALG) membranes in hydrated conditions, we observed the swelling of a fluorescently labeled membrane after immersion in a physiological buffer (PBS). To this end, the (CHI/ALG) film was built using CHI-A568 for fluorescence visualization by CLSM (Figure 7). The initial thickness of dry (CHI/ALG) ${ }_{200}$

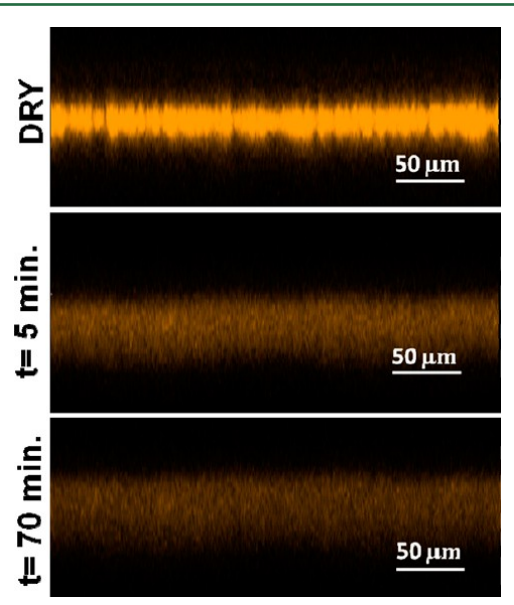

Figure 7. CLSM images of the swelling behavior of a labeled (CHIA568/ALG) ${ }_{200}$ membrane after immersion in a PBS buffer for different times.

membrane was $\sim 30 \mu \mathrm{m}$, which was consistent with the results of Figure 4C. After $5 \mathrm{~min}$ immersion in PBS, the membrane thickness was $\sim 65 \mu \mathrm{m}$, which represented a 2 -fold increase in thickness due to swelling. We noted that the membrane was then stable in solution with no more change in thickness.

Our results thus contrasted with those of Lutkenhaus et al. ${ }^{21}$ and Larkin et al., ${ }^{24}$ who reported that un-cross-linked multilayer films of poly(ethylene oxide) (PEO)/ $\mathrm{PAA}^{21}$ and $(\mathrm{HA} / \mathrm{CHI})^{24}$ disintegrated in a few minutes when exposed to a PBS solution. $^{21,24}$ In the case of hydrogen-bonded (PEO/PAA) membranes, ${ }^{21}$ the authors showed that cross-linking at high temperature $\left(105{ }^{\circ} \mathrm{C}\right.$ overnight) to form anhydrate bonds notably increased their stability. Indeed, the cross-linked membranes persisted for nearly four times as long as the 
unmodified (PEO/PAA) assemblies. They also remained in a swollen gellike state upon immersion in $\mathrm{PBS}^{21}$

In the case of (CHI/HA) FS membranes, ${ }^{24}$ the membranes made of 50 layer pairs and placed in PBS rapidly disintegrated. The loss of weight was higher than $90 \%$ within $5 \mathrm{~min}$. It was only by cross-linking them with glutaraldehyde that they could retain their weight when immersed in $\mathrm{PBS}^{24}$

Adhesion of Myoblasts on (CHI/ALG) Free-Standing Membranes. To check the potential of the (CHI/ALG) membranes for biomedical applications, adhesion tests were performed with a muscle cell line ( $\mathrm{C} 2 \mathrm{C} 12$ myoblasts). We selected this muscle cell line as it is commonly used as model cells in skeletal muscle tissue engineering. ${ }^{47}$ Besides, alginate has already been used as biomaterial for muscle cell growth. ${ }^{48}$ The first requirement for a material suitable for skeletal muscle tissue generation and further implantation is to support the interaction with muscle precursor cells.

We compared the upper sides of the membrane with the "substrate side", that is, the side that was in contact with the substrate prior to detachment of the film and is made of an initial layer of $\mathrm{CHI}$ ). Furthermore, we investigated whether the ending layer played a role in cell adhesion and compared $\mathrm{CHI}$ versus ALG-ending membranes (Figure 8). Cell density on the
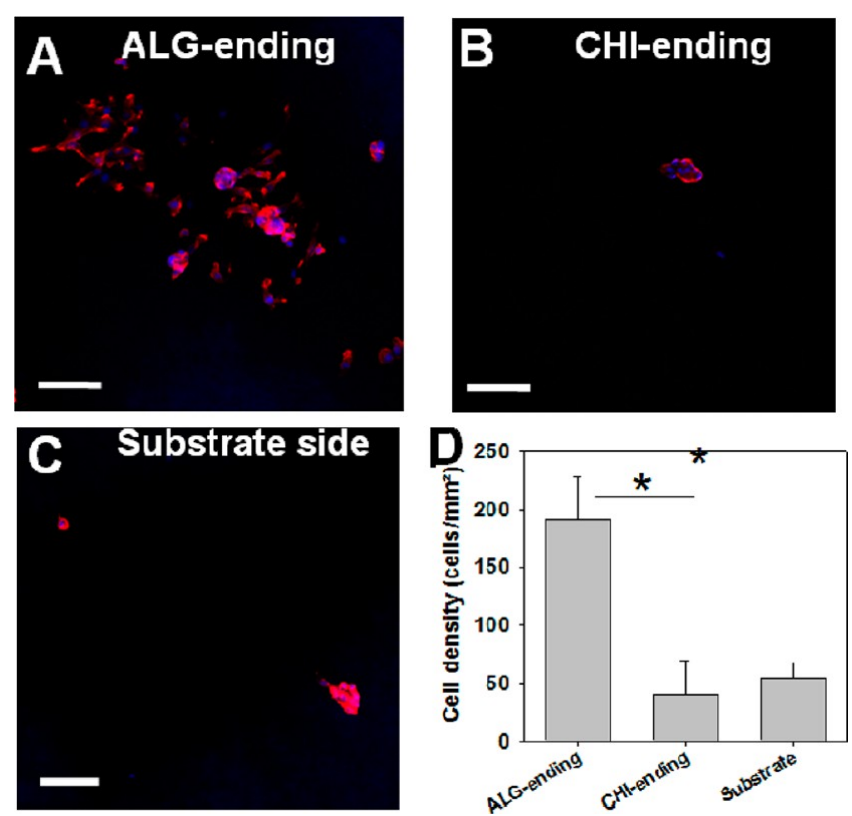

Figure 8. $\mathrm{C} 2 \mathrm{C} 12$ myoblast interaction with the $(\mathrm{CHI} / \mathrm{ALG})_{200} \mathrm{FS}$ membranes. (A-C) CLSM images of C2C12 cell adhesion after $24 \mathrm{~h}$ in growth medium. Cells were deposited on both sides of the freestanding films: upper side, ALG-ending (A) or CHI-ending (B) and substrate side (substrate, $\mathrm{C}$ ). The actin cytoskeleton and nuclei were stained by rhodamine-phalloidin and DAPI, respectively. Scale bar is $50 \mu \mathrm{m}$. (D) Cell density was determined for each experimental condition (substrate side and upper side ending by ALG or CHI); ${ }^{*} p$ $<0.05$.

FS membrane was quantified after $24 \mathrm{~h}$ of contact with the (CHI/ALG) FS membranes (Figure 8D). Few cells adhering as small clusters were observed on the $\mathrm{CHI}$-ending membranes (Figure 8B) and on the substrate side as well (Figure 8C). Conversely, cell adhesion was higher on the ALG-ending membranes at 200 cells $/ \mathrm{mm}^{2}$ (Figure $8 \mathrm{D}$ ).

Of note, although we did not measure the mechanical properties of these hydrated FS membranes made of 200 layer pairs, it is unlikely that a single layer of ALG might change the overall mechanical properties of the $\sim 60 \mu \mathrm{m}$ thick membrane. Also, the roughness of the FS membranes did not seem to play a major role as the substrate site of the membrane and upper side ending by $\mathrm{CHI}$ behaved similarly, although the upper side was more rough (Figure 2). For the (CHI/ALG) FS membranes, surface chemistry thus seems to play a major role in the myoblast cell response, ALG ending membranes being preferred by the cells. Our results are also consistent with previous data showing cell adhesion was low on CHI-ending multilayer films. ${ }^{49}$

All together, these results show that the (CHI/ALG) membrane may be further used for the culture of myoblasts and the delivery of active molecule to cells.

\section{CONCLUSIONS}

In summary, we have shown that thick free-standing membranes made of (CHI/ALG) multilayer films can be easily and reproducibly prepared in mild conditions without any postprocessing step. The optimal growth conditions were found when the $\mathrm{pH}$ of ALG was set to 3 and its concentration to $5 \mathrm{mg} / \mathrm{mL}$. Interestingly, these $4-35 \mu \mathrm{m}$ thick membranes were easy to handle with tweezers and were stable in a physiological buffer. In addition, they enabled the partial permeation of model drugs. The assembly of thick, detachable, biocompatible, and permeable free-standing membranes offers new perspectives for applications of these membranes in tissue engineering.

\section{AUTHOR INFORMATION}

\section{Corresponding Author}

*E-mail: catherine.picart@grenoble-inp.fr; jmano@dep. uminho.pt. Phone: +33(0)456529311 (C.P.); +35 1253 510900 (J.F.M.). Fax: +33(0)4 56529301 (C.P.); +35 1253 510909 (J.F.M.).

\section{Notes}

The authors declare no competing financial interest.

\section{ACKNOWLEDGMENTS}

This work was financially supported by Foundation for Science and Technology (FCT) through the Scholarship SFRH/BD/ $64601 / 2009$ granted to S.G.C. C.M. is indebted to Grenoble INP for financial support via a postdoctoral fellowship. This work was supported by the European Commission (FP7 Program) via a European Research Council starting grant (BIOMIM, GA 259370 to C.P.). C.P. is also grateful to Institut Universitaire de France and to Grenoble Institute of Technology for financial support. We thank Isabelle Paintrand for her technical help with the confocal apparatus and Patrick Chaudouet for his help with SEM imaging.

\section{REFERENCES}

(1) Decher, G.; Hong, J. D.; Schmitt, J. Thin Solid Films 1992, 210/ 211 (Part 2), 831-835.

(2) Tang, Z. Y.; Wang, Y.; Podsiadlo, P.; Kotov, N. A. Adv. Mater. 2006, 18, 3203-3224.

(3) Burke, S. E.; Barrett, C. J. Biomacromolecules 2003, 4, 1773-1783.

(4) Shiratori, S. S.; Rubner, M. F. Macromolecules 2000, 33, 42134219.

(5) Schlenoff, J. B.; Ly, H.; Li, M. J. Am. Chem. Soc. 1998, 120, 76267634.

(6) Schoeler, B.; Kumaraswamy, G.; Caruso, F. Macromolecules 2002, $35,889-897$. 
(7) Shen, L.; Chaudouet, P.; Ji, J.; Picart, C. Biomacromolecules 2011, 12, 1322-31.

(8) Fu, J. H.; Ji, J.; Shen, L. Y.; Kueller, A.; Rosenhahn, A.; Shen, J.

C.; Grunze, M. Langmuir 2009, 25, 672-675.

(9) Shen, L.; Chaudouet, P.; Ji, J.; Picart, C. Biomacromolecules 2011, 12, 1322-1331.

(10) Boudou, T.; Crouzier, T.; Ren, K.; Blin, G.; Picart, C. $A d v$. Mater. 2010, 22, 441-467.

(11) Hynes, R. O. Science 2009, 326, 1216-9.

(12) Mano, J. F.; Silva, G. A.; Azevedo, H. S.; Malafaya, P. B.; Sousa, R. A.; Silva, S. S.; Boesel, L. F.; Oliveira, J. M.; Santos, T. C.; Marques,

A. P.; Neves, N. M.; Reis, R. L. J. R. Soc. Interface 2007, 4, 999-1030.

(13) Crouzier, T.; Boudou, T.; Picart, C. Curr. Opin. Colloid Interface Sci. 2010, 15, 417-426.

(14) Delcea, M.; Mohwald, H.; Skirtach, A. G. Adv. Drug Delivery Rev. 2011, 63, 730-747.

(15) Veerabadran, N. G.; Goli, P. L.; Stewart-Clark, S. S.; Lvov, Y. M.; Mills, D. K. Macromol. Biosci. 2007, 7, 877-82. Wilson, J. T.; Cui, W. X.; Kozovskaya, V.; Kharlampieva, E.; Pan, D.; Qu, Z.; Krishnamurthy, V. R.; Mets, J.; Kumar, V.; Wen, J.; Song, Y. H.; Tsukruk, V. V.; Chaikof, E. L. J. Am. Chem. Soc. 2011, 133, 70547064.

(16) Mets, J. M.; Wilson, J. T.; Cui, W.; Chaikof, E. L. Adv. Healthcare Mater. 2013, 2, 266-70.

(17) De Geest, B. G.; De Koker, S.; Sukhorukov, G. B.; Kreft, O.; Parak, W. J.; Skirtach, A. G.; Demeester, J.; De Smedt, S. C.; Hennink, W. E. Soft Matter 2009, 5, 282-291. Such, G. K.; Tjipto, E.; Postma, A.; Johnston, A. P.; Caruso, F. Nano Lett. 2007, 7, 1706-10.

(18) Jiang, C.; Tsukruk, V. V. Adv. Mater. 2006, 18, 829-840.

(19) Tang, Z. Y.; Kotov, N. A.; Magonov, S.; Ozturk, B. Nat. Mater. 2003, 2, 413-418.

(20) Mamedov, A. A.; Kotov, N. A. Langmuir 2000, 16, 5530-5533. Jiang, C. Y.; Markutsya, S.; Tsukruk, V. V. Adv. Mater. 2004, 16, 157161.

(21) Lutkenhaus, J. L.; Hrabak, K. D.; McEnnis, K.; Hammond, P. T. J. Am. Chem. Soc. 2005, 127, 17228-17234.

(22) Gheith, M. K.; Sinani, V. A.; Wicksted, J. P.; Matts, R. L.; Kotov, N. A. Adv. Mater. 2005, 17, 2663-+. Lin, Y. H.; Jiang, C.; Xu, J.; Lin, Z. Q.; Tsukruk, V. V. Soft Matter 2007, 3, 432-436.

(23) Fujie, T.; Matsutani, N.; Kinoshita, M.; Okamura, Y.; Saito, A.; Takeoka, S. Adv. Funct. Mater. 2009, 19, 2560-2568.

(24) Larkin, A. L.; Davis, R. M.; Rajagopalan, P. Biomacromolecules 2010, 11, 2788-2796.

(25) Cauchie, H. M. Hydrobiologia 2002, 470, 63-96.

(26) Rinaudo, M. Polym. Int. 2008, 57, 397-430.

(27) Lee, K. Y.; Mooney, D. J. Prog. Polym. Sci. 2012, 37, 106-126.

(28) Pawar, S. N.; Edgar, K. J. Biomaterials 2012, 33, 3279-3305.

(29) Kumar, M.; Muzzarelli, R. A. A.; Muzzarelli, C.; Sashiwa, H.; Domb, A. J. Chem. Rev. 2004, 104, 6017-6084. Boateng, J. S.; Matthews, K. H.; Stevens, H. N. E.; Eccleston, G. M. J. Pharm. Sci. 2008, 97, 2892-2923.

(30) Rowley, J. A.; Madlambayan, G.; Mooney, D. J. Biomaterials 1999, 20, 45-53.

(31) da Silva, R. M. P.; Mano, J. F.; Reis, R. L. Macromol. Chem. Phys. 2008, 209, 1463-1472.

(32) Terbojevich, M.; Cosani, A.; Muzzarelli, R. A. A. Carbohydr. Polym. 1996, 29, 63-68.

(33) He, H.; Cao, X.; Lee, L. J. J. Controlled Release 2004, 95, 391402. Schwarte, L. M.; Peppas, N. A. Polymer 1998, 39, 6057-6066.

(34) Duarte, M. L.; Ferreira, M. C.; Marvao, M. R.; Rocha, J. Int. J. Biol. Macromol. 2002, 31, 1-8.

(35) Wang, X. H.; Li, D. P.; Wang, W. J.; Feng, Q. L.; Cui, F. Z.; Xu, Y. X.; Song, X. H.; van der Werf, M. Biomaterials 2003, 24, 32133220.

(36) Valentin, R.; Bonelli, B.; Garrone, E.; Di Renzo, F.; Quignard, F. Biomacromolecules 2007, 8, 3646-3650.

(37) Lawrie, G.; Keen, I.; Drew, B.; Chandler-Temple, A.; Rintoul, L.; Fredericks, P.; Grondahl, L. Biomacromolecules 2007, 8, 2533-2541.
(38) Picart, C.; Schneider, A.; Etienne, O.; Mutterer, J.; Schaaf, P.; Egles, C.; Jessel, N.; Voegel, J. C. Adv. Funct. Mater. 2005, 15, 17711780.

(39) Lopez-Perez, P. M.; da Silva, R. M. P.; Pashkuleva, I.; Parra, F.; Reis, R. L.; San Roman, J. Langmuir 2009, 26, 5934-5941.

(40) Jaber, J. A.; Schlenoff, J. B. J. Am. Chem. Soc. 2006, 128, 29402947.

(41) Hajicharalambous, C. S.; Lichter, J.; Hix, W. T.; Swierczewska, M.; Rubner, M. F.; Rajagopalan, P. Biomaterials 2009, 30, 4029-4036.

(42) Michel, M.; Izquierdo, A.; Decher, G.; Voegel, J. C.; Schaaf, P.; Ball, V. Langmuir 2005, 21, 7854-9. Porcel, C.; Lavalle, P.; Decher, G.; Senger, B.; Voegel, J. C.; Schaaf, P. Langmuir 2007, 23, 18981904.

(43) Cai, J.; Wu, L.; Qi, X. P.; Calzi, S. L.; Caballero, S.; Shaw, L.; Ruan, Q.; Grant, M. B.; Boulton, M. E. PLoS One 2011, 6, 15. Iskakov, R. M.; Kikuchi, A.; Okano, T. J. Controlled Release 2002, 80, 57-68.

(44) Vodouhe, C.; Le Guen, E.; Garza, J. M.; Francius, G.; Dejugnat, C.; Ogier, J.; Schaaf, P.; Voegel, J. C.; Lavalle, P. Biomaterials 2006, 27, 4149-4156. Volodkin, D.; Skirtach, A.; Mohwald, H., LbL Films as Reservoirs for Bioactive Molecules. In Bioactive Surfaces; Borner, H. G., Lutz, J. F., Eds.; Springer-Verlag: Berlin, 2011; Vol. 240, pp 135-161; Crouzier, T.; Ren, K.; Nicolas, C.; Roy, C.; Picart, C. Small 2009, 5, 598-608.

(45) Matsuyama, H.; Tamura, T.; Kitamura, Y. Sep. Purif. Technol. 1999, 16, 181-187.

(46) Liang, S. M.; Zhang, L.; Xu, H. J. Membr. Sci. 2007, 287, 19-28. Xu, D.; Loo, L. S.; Wang, K. J. Appl. Polym. Sci. 2011, 122, 427-435.

(47) Stern-Straeter, J.; Riedel, F.; Bran, G.; Hormann, K.; Goessler, U. R. In Vivo 2007, 21, 435-444.

(48) Rowley, J. A.; Mooney, D. J. J. Biomed. Mater. Res. 2002, 60, 217-223. Boontheekul, T.; Hill, E. E.; Kong, H. J.; Mooney, D. J. Tissue Eng. 2007, 13, 1431-1442. Rossi, C. A.; Pozzobon, M.; De Coppi, P. Organogenesis 2010, 6, 167-172.

(49) Richert, L.; Lavalle, P.; Payan, E.; Shu, X. Z.; Prestwich, G. D.; Stoltz, J. F.; Schaaf, P.; Voegel, J. C.; Picart, C. Langmuir 2004, 20, 448-458. 